\title{
Exploring Public-Private Partnership in Preschool Education Provision: Potential for Socio-Economic Development
}

\author{
Vitaly Radsky \\ Center for Innovations in Education, Baku, Azerbaijan \\ Aynur Nabiyeva \\ Center for Innovations in Education, Baku, Azerbaijan \\ Ulviyya Mikayilova \\ Center for Innovations in Education, Baku, Azerbaijan
}

\section{Introduction}

The importance of education in socio-economic development has long been emphasized at the intersection of economic disciplines. Since the 1970s human capital development theory made a particularly strong argument for the positive long-term effects of education investment on economic growth.

The World Economic Forum's Global Competitiveness Report shows that "competitive economies drive productivity enhancements that support high incomes by ensuring that the mechanisms enabling solid economic performance are in place" (2012, p. 4). The report is made up of twelve pillars that measure competitiveness defined as "the set of institutions, policies, and factors that determine the level of productivity of a country" $(2012$, p. 8). Four of these pillars, including health and primary education are included in the "basic requirements subindex" and are described as the backbone of factor driven economies. An additional six pillars including higher education and training, good market efficiency, labor market efficiency, financial market development, and technological readiness are categorized keys for efficiency-driven economies. Arguably, over the next generation Azerbaijan will attempt to make the transition from factor-driven (energy and agriculture) to efficiency-driven, but in order to make this transition, primary and pre-primary education will have to provide a solid foundation for the further development of higher education and labor market efficiency. Worker productivity is one of the core factors of economic growth and accessible, quality education plays a significant role in ensuring productivity. 
Thus, on the policy level it is important to ensure sufficient, long run resource allocation in education to provide the necessary human resources for the development of business and the production of value-intensive products.

Early childhood education is the very first level of public education. Ensuring full access to quality and affordable ECE is the starting point for education's role in human capital development. In addition to being the first stage of a person's journey through life, numerous longitudinal studies on human development have found that the brain develops fastest within the first three years of life. The core of a child's cognitive, socio-emotional and health development is made during these years. Global studies on the long-term impact of early childhood education have shown higher readiness for primary schools, better overall educational outcomes, higher on-time graduation rates, higher future job success, and a lower rate of behavioral problems, including involvement in crimes (Vegas \& Santibanez, 2010; Heckman, 2006). One of the most prominent longitudinal studies measuring the long-term effects of ECE was conducted with children attending the High/Scope Perry Preschool Program in the town of Yipsilanti, Michigan from 1962 through 1967. Following these children (and the control group) for over 40 years showed that children initially identified as at-risk who attended preschool were more likely to have graduated from high school, had significantly higher median annual earnings, and had significantly fewer lifetime arrests along with several other positive indicators (Calman \& Tarr-Whelan, 2005, p. 18). Overall, translating the findings into economic terms, the study concluded that over forty years, for every dollar spent on the High/Scope Perry preschool program brought a 12.90 dollar return.

It should also be noted that the effects of early childhood experiences are doubly important, due to "the extreme plasticity of the brain during these periods is a double-edged sword that leads to both adaptation and vulnerability" (Vegas \& Santibanez, 2010, p. 33). In other words, while nutrition and social environment play a significant role in brain development and affect outcomes at further stages of a child's development, malnutrition and lack of or inadequate social experiences can severely damage, or delay a child's development resulting in future neural and behavioral problems. Quality early childhood education is central to ensuring crucial positive social experiences, which are part of the foundation for future development. Although the effects of any educational investment are influenced by contexts, preschool interventions have been found to be especially beneficial for poor and otherwise 'at-risk' or 'disadvantaged' children. There is now a general 
international consensus on the importance of prioritizing preschool investment for human capital development. For example, the graph below from the National Scientific Council on the Developing Child supports the general idea of timesensitivity when investing in preschool education: the earlier the investment in preschool education takes place the higher the return on investment.

Rates of Return on Investment in Human Capital as a Function of Age

\section{Return on Investment Over Time}
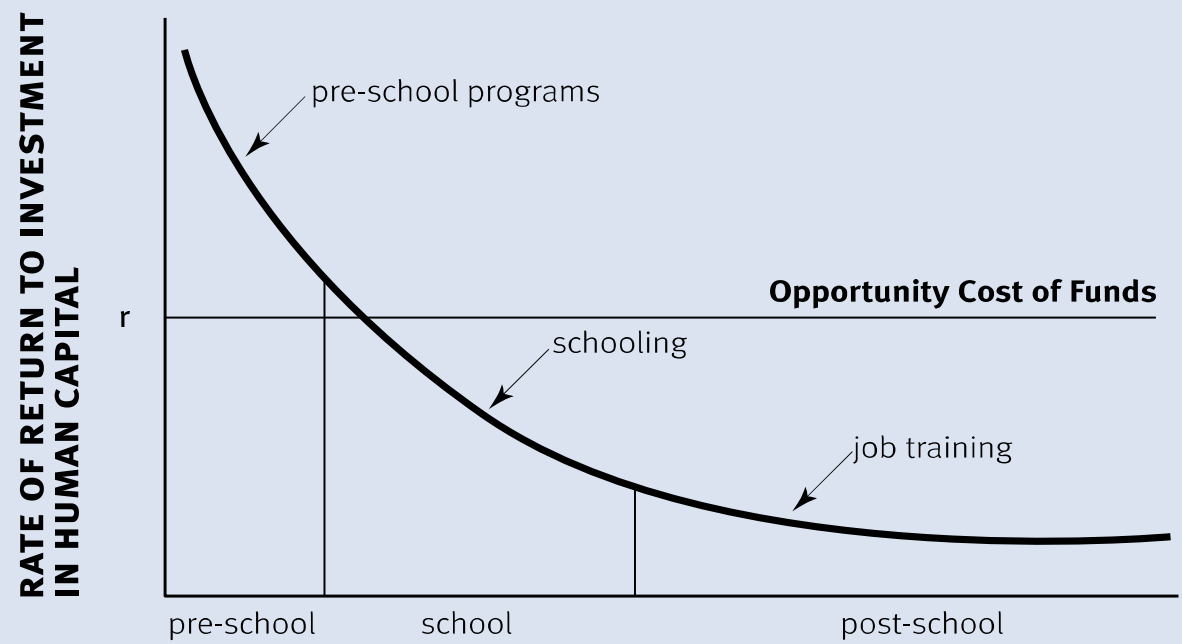

AGE

Rates of return to investment in human capital as function of age when the investment was initiated. The data were derived from a life cycle model of dynamic human capital accumulation with multiple periods and credit constraints. Investments were initially set to be equal across all ages. ' $r$ ' represents the cost of the funds. Data are from Cunha et al (2005).

Source: Knudsen, et al. ${ }^{13}$

Figure 1 Source: National Scientific Council on the Developing Child, 2007

Despite the numerous benefits of investments into preschool education, there is an increasing tendency in research and practice to view benefits of ECE as contingent on quality. According to "Starting Strong III," the OECD report on ECEC, "if quality is low, it can have long-lasting detrimental effects on child development, instead of bringing positive effects" (p.9). ${ }^{1}$

\footnotetext{
${ }^{1}$ Generally, quality of preschool education focuses in its process and structural
} 
In Europe and the United States, the growing attention to investing in early childhood education is also related to allowing parents, especially mothers, return to (become fully productive in) the labor force. Especially in the case of single mothers, quality preschool education is necessary to ensure the economic stability of the family. ${ }^{2}$ For example, "Like adequate highways and housing, early education is part of the infrastructure that supports businesses and parents' ability to work" (Calman \& Tarr-Whelan, 2005, p. 7).

In $2002 \mathrm{EU}$ member states included provision for childcare services as part of European Employment Strategy. The Barcelona European Council set targets of achieving childcare provision for $90 \%$ of children between the age of 3 to mandatory school age, and 33\% for those under 3 in all EU member states by 2010 with the aim of removing disincentives for women employment. The progress made towards these objectives has been varying across member states. The rationale for this decision is multifaceted. First, this speaks directly to the necessity of encouraging more people to enter the labor force. Accommodating parents, especially mothers with different types of ECEC (such as day-care centers and similar) can enable them to enter the workforce and acquire full or part-time employment. Second, it is seen as a pathway to reaching equality between men and women particularly in employment practices (such as gap in pay) to eliminate any discrimination based on gender. Accessible and affordable childcare services can level the employment opportunities for parents. Overall, increasing women's participation in the labor force and their employment rate is directly related to the universal provision of childcare services and can be an important contributing factor to economic growth. It should also be noted that the Lisbon summit, which recognizes women, largely nurtured the Barcelona summit targets as an integral and essential part of national labor force. Thus to stimulate the participation of women in the workforce several strategies were considered in an effort to create the opportunities women necessitate to enter the labor market. One of these strategies is the provision of childcare services.

components. Process quality refers to interactions between child and teacher, child and parents, overall educational settings and available materials. Structural quality mostly focuses on the pedagogical aspect of ECE, including class size, student-teacher ratio, qualification and compensation of teachers and personnel and similar indicators. "Care" and "education" components as the report describes constitute the fundamental differences in quality goals. Combining these two helps to provide a holistic service provision of a child for his or her full development.

${ }^{2}$ This is particularly important in integration of women trafficking survivors into society and labor force. 


\section{Early Childhood Education in Azerbaijan: Situation overview}

In Azerbaijan, early childhood education is largely defined as preschool education and mostly provided by public kindergartens and nurseries. This paper deals with access, quality, and affordability of the existing ECED system in Azerbaijan as well as reviewing gaps in the state-level policies such as underinvestment and the legislative framework, which also directly affect these issues on a macro level.

In 2008, the State Program on Poverty Reduction and Sustainable Development in the Republic of Azerbaijan for 2008-2015 set a target to double the share of children of pre-school age (3-6) completing preschool by 2015 . In fact, the enrollment rate has actually decreased during this time period: from 17.2\% in 2007 to $16 \%$ in 2013 . Preschool access is particularly low in rural areas. For example, while $23.4 \%$ of children $1-5$ years of age attend preschool in urban areas, only $8.6 \%$ do so in rural areas (Ministry of Education Report 2012). A needs assessment study conducted by the Center for Innovations in Education (CIE) in one of the western regions of Azerbaijan shows that the major reasons children do not attend preschool is related to parents' dissatisfaction with existing kindergarten, lack of a kindergarten in a nearby area or lack of open slots, and lack of transportation to an existing kindergarten. ${ }^{3}$ These can be generalized across the country where public kindergartens are usually the only type of preschool service provided in rural areas.

On a national level, there is a significant drop from levels under the Soviet Union and this reflects a drastic decrease in preschool enrollment from over180 thousand in 1991 to 111 thousand over the next 10 years. This dramatic decrease was largely because of the Nagorno-Karabakh war that followed independence. After the war, large numbers of IDP families were relocated to public buildings, including kindergartens around the regions. Enrollments rates leveled off at around 111 thousand from 2001 to 2006, before dipping again due to a largely unsuccessful state-led preschool privatization initiative that is reviewed later in the paper. The levels have only begun to recover over the last couple years.

The 2011 Progress International Reading Literacy (PIRLS) study also discusses the importance of preprimary education for shaping children's reading literacy stating, "Besides giving students an early start in school and life, preprimary education provides an avenue for overcoming children's disadvantages and can help to break the generational cycles of poverty and low achievement" (International Association

${ }^{3}$ Needs Assessment Study, Center for Innovations in Education, 2011 
for the Evaluation of Educational Achievement (IEA), 2012, p. 12). The same report shows that Azerbaijan's preschool enrollment rate is the lowest among the 45 countries in the study.

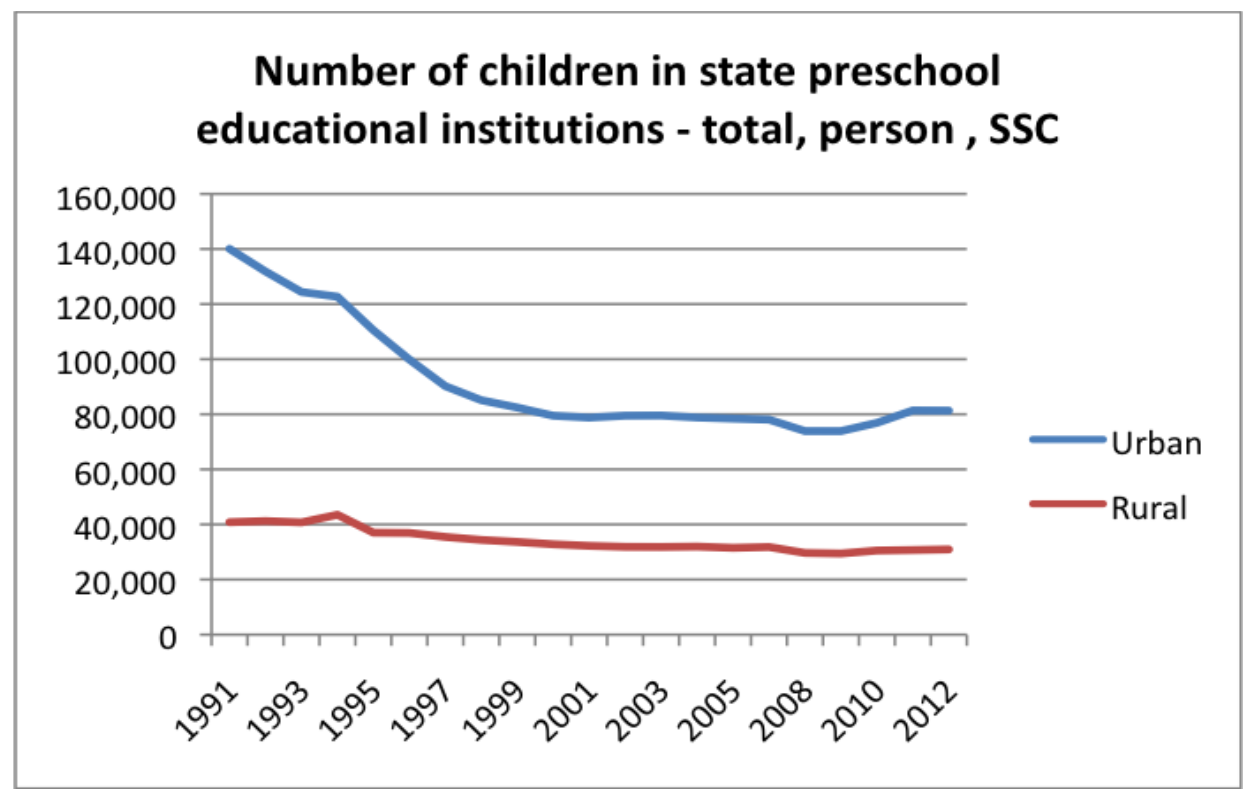

Figure2. Source: http://www.stat.gov.az/source/education/indexen.php

The 2006 Presidential Decree on "Privatization of some institutions and enterprises in the fields of health, education, sport and culture" included a list of 240 kindergartens ${ }^{4}$ under the Ministry of Education that would be privatized. The overall goal of this initiative was to improve and increase the quality of social services (including kindergartens) provided at that time by public institutions. However, a monitoring study of 36 preschools on privatization in Baku conducted by a local NGO shows multi-layered issues linked to this process of privatization, and detrimental consequences of the overall privatization initiative on the preschool community. For example, in the majority of the kindergartens visited during the study lack of nutrition was a problem as government subsidies ceased. Another observed consequence was the demolition of the green area within the preschool location. In addition, the number of pedagogical staff in preschools decreased dramatically, along with the enrollment rate during privatization (Sosial İnkişafa Dəstək İctimai Birliyi "Uşaq bağçalarının özəlləşdirilməsi prosesinin monitorinqi").

\footnotetext{
${ }^{4}$ Məktəbəqədərtəhsilsahəsiüzrə 2008-ci ildəgörülmüşişlərədairhesabat (2008).Available:http://edu.gov.az/view.php?lang=az\&menu=315\&id=473
} 


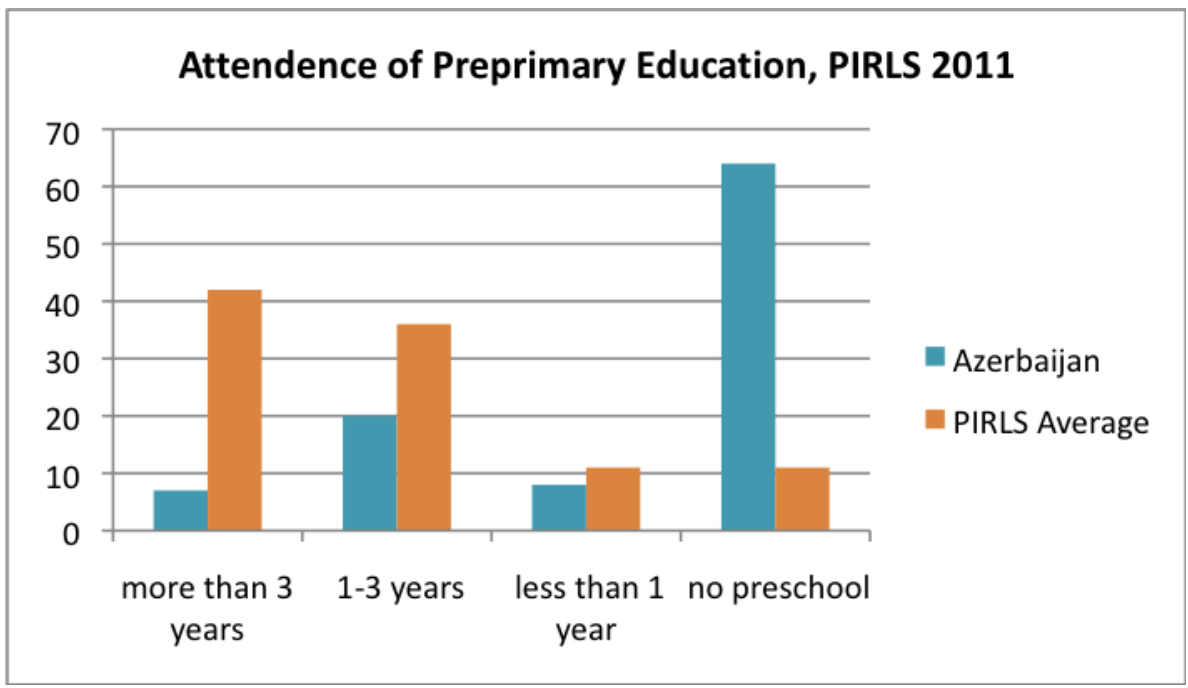

Figure3Data from the 2011PIRLS Assessment available at http://timssandpirls.bc.edu/pirls2011/international-results-pirls.html.

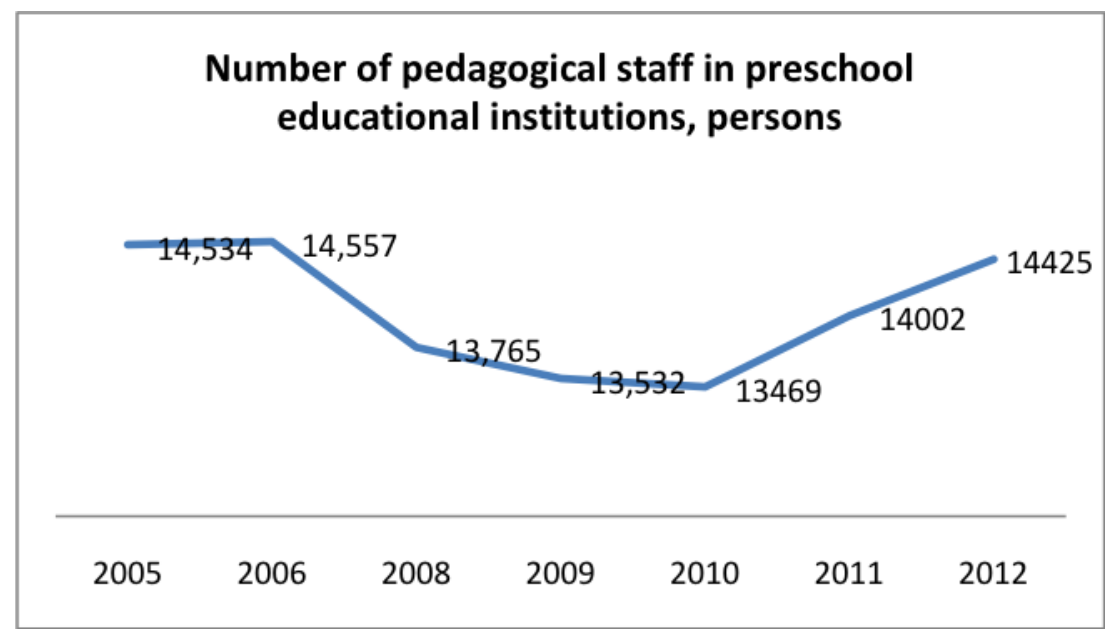

Figure4. Compiled with data from the State Statistics Committee. Available from http://www.stat.gov.az/source/education/ (Education- preschool educational institutions)

In one of the privatized schools, the staff reported that the identity of the owner was never disclosed and this caused issues within the preschool. Overall, the major problems are related to lack of transparency in the process of privatization, discrepancies between the initial goals and objectives of the privatization initiatives 
and the actual privatization process which rather than improving services led to a reduction in the number of staff and total number of preschool institutions. Whereas the main goal behind these initiatives was the multi-layered development of preschool services, in reality as a result of these initiatives there was a decrease in of preschool service provision and enrollment rate.

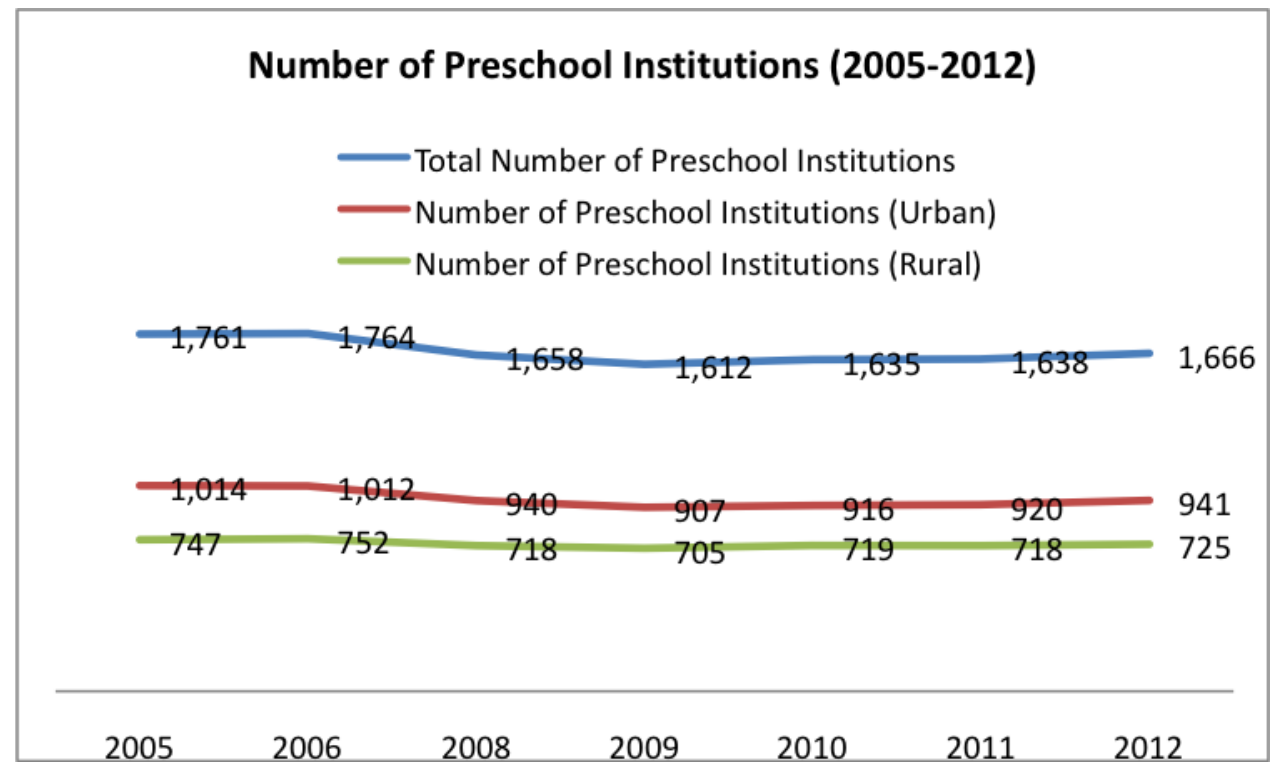

Figure5. Compiled with data from the State Statistics Committee. Available from http://www.stat.gov.az/source/education/ (Education- preschool educational institutions)

In general, public spending on education in Azerbaijan has been gradually increasing, however, it remains lower compared to spending in the region. Education investment as a share of GDP is lower (2.8\%) compared to the regional and OECD average of $5.1 \%$. The following graph compares overall public spending on the education sector among relevant Economic Cooperation Organization (ECO) countries. In 2010, spending on education in Azerbaijan comprised only $2.8 \%$ of GDP compared to $4.8 \%$ in Iran Islamic Republic, $5.8 \%$ in Kyrgyz Republic and 4\% in Tajikistan. The indicator for public spending also remains low at approximately $10 \%$ of the national budget expenditure compared to $20 \%$ in Iran, $19 \%$ in Kyrgyz Republic and $15 \%$ in Tajikistan. Currently, spending on preschool education comprises less than $1 \%$ of the national budget and $10 \%$ of the allocated funding for overall education. 


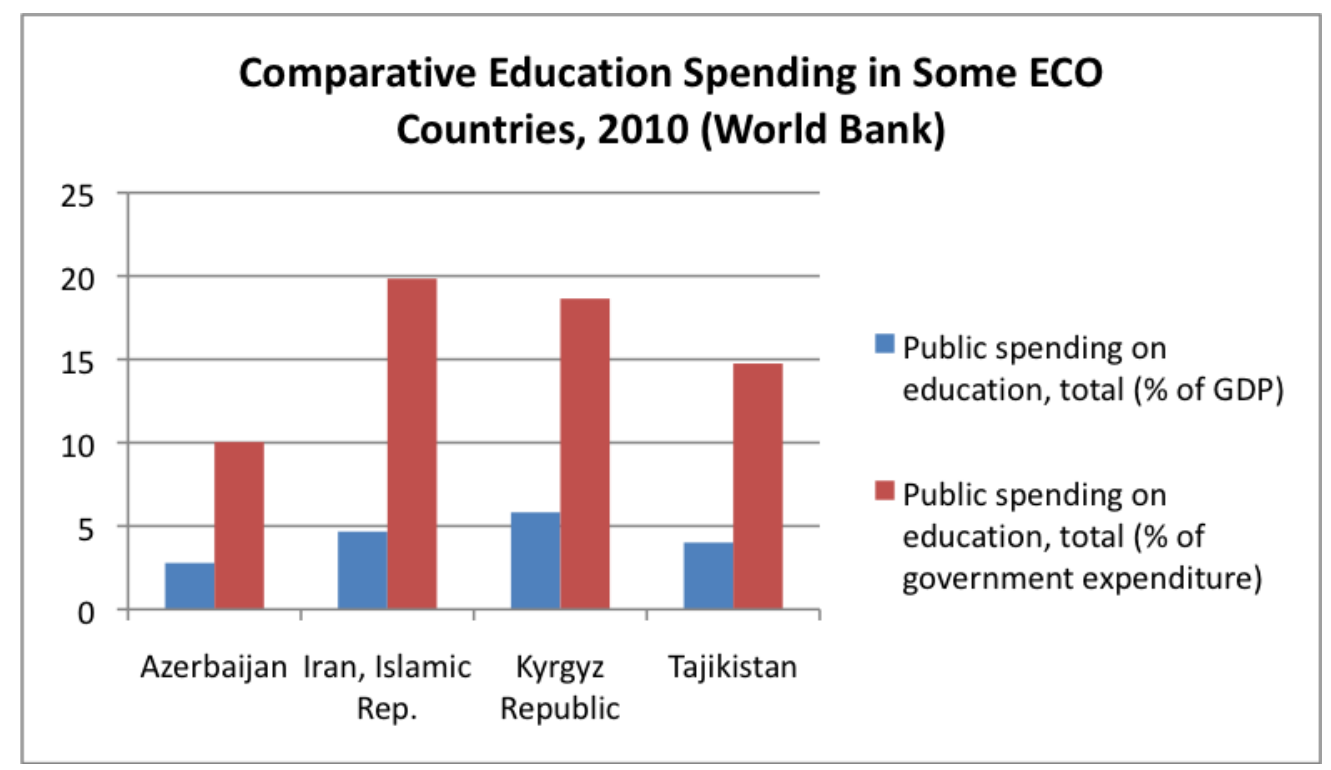

Figure6. ECO countries were selected based on availability of relevant data. Source: http://databank.worldbank.org/data/views/reports/tableview.aspx

Azerbaijan's national target for unemployment aims at a decrease of the current unemployment level by approximately two times to $3 \%-4 \%$ by 2015 (State Program on Poverty Reduction and Sustainable Development, 2008). As women constitute $49 \%$ of the economically active population according to State Statistics Committee, entry of more women into the labor market plays a significant role in increasing the employment rate. Again, from an employment standpoint, the provision of affordable and accessible childcare facilities is very important. Increased employment opportunities for women also contribute to the economic independence of mothers, decreased risk of poverty, and ultimately acts as a safeguard against child poverty. Currently, education is the second largest field of employment for women after health and human services. Considering the fact that the pedagogical staff employed in preschool institutions are nearly exclusively women, the impact of the privatization initiative can be observed in the employment rate of women in the field. Following privatization of kindergartens, the employment rate for women decreased from $71 \%$ in 2006 to $69.7 \%$ in 2007 and continued to decrease to $67 \%$ for the next years. ${ }^{5}$

\footnotetext{
${ }^{5}$ State Statistical Committee http://www.stat.gov.az/source/gender/indexen.php
} 


\section{Share of Women of Total Employees by Economic Activities, \% (SSC)}

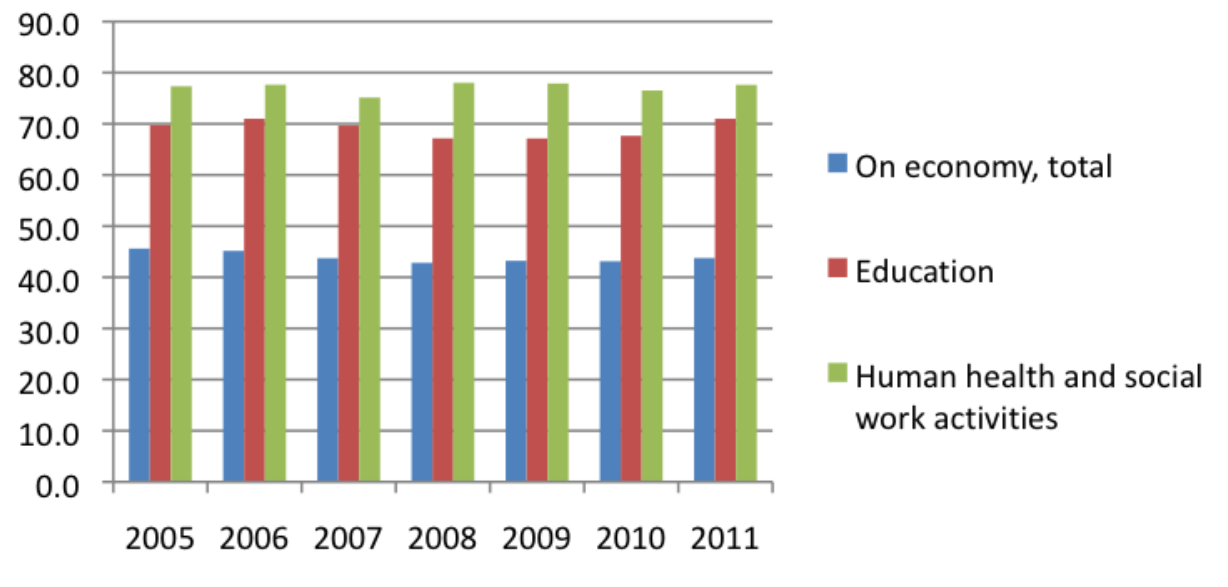

Figure7. Source: http://www.stat.gov.az/source/labour/indexen.php

According to information obtained directly from the Ministry of Education, the 14,614 pedagogical staff employed by state, non-state and private preschool institutions across the country are all women. Based on estimated calculations, which consider current coverage of preschool aged children at only $16 \%$, the provision of universal access to preschool would create approximately 76,723 more jobs for women. Given that different models of partnerships and alternative models are applied, creation of these jobs does not necessarily translate into a financial burden as it is fully covered by a government subsidy. Involvement of a wide range of public and private actors in the provision of preschool services can play an important role in increasing women's participation rate in the national labor force.

In 2007 the President approved "Programme for Modernization of Pre-school education in the Republic of Azerbaijan (2007-2010)." It was an important step to for preschool improvement from a number of aspects, including infrastructure and quality-wise reforms. It was also important in terms of bringing together multiple stakeholders and a wide range of state level decision- makers such as the Ministry of Economic Development, State Statistics Committee, Ministry of Education and many others. The program introduced several initiatives such as new preschool textbook materials, proposal of changes to the nutrition norms, exemplary contract with parents on provision of preschool services, commentary and proposals to the State Statistical Committee on preschool data/indicators, proposal to the President 
on increasing social status and material provision of pedagogical staff in preschools within the Program. However, most of the results towards these outcomes were infrastructural improvements. ${ }^{6}$

In spite of the incremental changes introduced, the Programme for Modernization of Pre-school Education in the Republic of Azerbaijan" did not result in substantial improvement in preschool education, particularly for disadvantaged children. According to SSC data and a UNICEF study in Azerbaijan most of the children who access preschool education are those from affluent urban families, ${ }^{7}$ and provision of preschool in rural areas has in fact decreased from $11.5 \%$ in 2006 to $8.6 \%$ in $2012 .{ }^{8}$ Globally, numerous studies on assessing the impact and effectiveness of various ECED confirmed that preschool has its highest effects on children from disadvantaged communities. It helps to break the intergenerational cycle of poverty and gradually reduce the inequality among different groups in society. Thus provision of quality preschool services for particularly low-income families in rural areas should be a priority of expanding quality preschool services across the country.

Local and international CSOs in partnership with the Ministry of Education piloted alternative models of ECE projects in several regions across the country. These models are relatively new and a comprehensive policy-level study to explore the feasibility of integrating these models on a national scale still needs to be conducted. However, at the preliminary stage, the introduced models can provide viable access and development for early childhood education in rural areas where the current public kindergarten system does not have capacity and resources to otherwise reach these children. Given such a low coverage of preschool education in the country and a massive disparity when it comes to access in rural and urban areas, achieving preschool provision for all children exclusively through statesponsored programs and institutions does not seem feasible both financially and administratively. Preschool investment has remained low at $0.73 \%$ of national budget. To provide universal access to all children with rough estimations the state would need to build an additional 8,747 kindergartens, which would mean

\footnotetext{
${ }^{6}$ Ministry of Education Reports. Available : http://edu.gov.az/view.php? lang=az\&menu $=315$

${ }^{7}$ Cheng, I-Feng E. Early Childhood Education in Azerbaijan: Expanding Access to Quality ECE. UNICEF, Paper 6, Out of School Children Paper Series. Available: http://www.unicef.org/ceecis/ECE.pdf ${ }^{8}$ State Statistics Committee Reports (Population / Statistical yearbook / Children in Azerbaijan) http://www.stat.gov.az/source/demography/au/indexen.php
} 
increasing the share of preschool expenses to $3.83 \%$ of the national budget. This means increasing the current preschool resource allocation by more than five times. Whether this is feasible considering the current government expenditure conditions is highly unlikely, but expanding policy solutions to involve actors from across the private and civil society sectors can provide another option for lower-cost ECE coverage across Azerbaijan. If Azerbaijan wants to gain a comparative advantage in the international community by investing in its human capital, the state needs to expand preschool services to all children across the country. The 2011 OECD report on regional competitiveness emphasizes human capital development as one of the three policy priority areas. The inclusiveness of policy-making process highlighted in the report should also translate on design and implementation of preschool provision. Provision of preschool services will only benefit from establishing public-private dialogue as the perception of different stakeholders differs on the effectiveness of policies, it is important to ensure their involvement ${ }^{9}$.

\section{Public-Private Partnerships: A new option}

The fields of finance and economics have suggested different frameworks to provide a theoretical model of public-private partnerships (PPP). Whereas some literature distinguishes PPPs from privatization, outsourcing, deregulation, some authors also give a broader definition to PPPs considering the above-listed partnerships as different categories within a broader PPP framework. The partnership differs from other more traditional forms of cooperation (such as contracting) mainly in the type of relationship between partners. Whereas, contracting involves one side with control over all strategic and developmental aspects, the other side acts only as an implementer. A public-private partnership (PPP) suggests a more equal relationship where both sides cooperate in decision making and planning. The common conclusion is that PPP is a means to deliver public services through private actors and PPPs have been most extensively used in delivering core infrastructure such as roads, bridges, water supply etc. More recently, however, public-private partnerships have also extended to managing social services such as hospitals and schools.

PPP can also be defined as a way to provide private financing for the delivery of public services. Yescombe(2007) places the PPP notion within the context of New Public Management. NPM is usually characterized by decentralization of government, output or performance-based measurements for public services,

${ }^{9}$ OECD, 2011, p. 41 
contracting out public services to private sectors among other elements (p. 16). Two of the most important factors in decentralization and privatization are management and financing. The combination of public or private management and public or private financing creates four possible categories of state-private cooperation beyond the traditional fully public or fully private division.

Yescombe(2007) notes that the fast growth of the PPP model is due to its budgetary benefits. Because financing is provided by the private party, the public budget does not face immediate charges. Instead this financing is paid back over time by users through service fees. The PPP costs usually are not reflected in public budgets and "the realistic choice, given budgetary constraints, is generally not between PPP and public-sector procurement of the Facility, but between PPP and no investment at all" (p. 17).

Brinkerhoff (2002) describes two dimensions of cooperation, organizational identity and mutuality, whose interaction creates different styles of cooperation between organizations. Mutuality refers to the "spirit of the partnership principle" and "entails respective rights and responsibilities of each actor to the others" in the provision of the service (Brinkerhoff, 2002, p. 22). A highly mutual relationship is one in which the objectives are consistent with the mission and goals of each party.

On the other hand, organizational identity describes the distinctness of what each organization brings to the table in terms of mission, values, and especially competitive advantage. Creating a partnership matrix consisting of organizational identity and mutuality, each scoring high or low Brinkerhoff (2002) shows that, partnership seems like a win-win situation of high mutuality or alignment and the maintenance of individuality, or organizational identity. The drawback then, is only the difficulty in finding and maintaining partners with which long-term, mutually beneficial, and dynamic relationships can be built.

With the increased environmental difficulties in developing countries such as a common lack of trust between civil society and the state, lower capacities on both sides, and a strong tradition of full state autonomy in service implementation, it is no surprise that Jutting (1999) writes "implementation [of PPPs] is still not very common in developing countries (p. 2). Thus, despite their potential, PPPs are highly context specific to both the country context, the micro-environment created by the potential partners, and by the service that needs to provided. Jutting (1999) outlines three general functions that need to be clearly delineated in a PPP: service 
provision, financing, and regulation and monitoring. There is thus a huge number of different forms a PPP could take, and this form is determined by issues such as the degree of control desired by the government, capacity of both sides in each function, the legal framework for monitoring and regulation, and the availability of financial resources from public or private sources (Gentry and Fernandez, 1998 from Jutting).

One of the major benefits for PPP as an alternative model in a preschool provision is that, unlike privatization, government or the state agency involved in the partnership remains directly politically accountable for a service provided by the PPP. This relationship went largely missing in the 2006 privatization initiative of the kindergartens in Azerbaijan. The fact that government did not have oversight and accountability over the privatized kindergartens, led to results that were largely unfavorable in terms of public service delivery, that is preschool provision for children.

Public-private partnerships are a popular but poorly defined type of relationship between state and non-state actors. Such arrangements seem to combine the best of both worlds - deep cooperation between organizations with maintained individuality and concretely defined roles and responsibilities - and have potential for providing both cost-efficiency and quality of service. However, the difficulty of creating and maintaining such an involved partnership and the diversity of models available make partnerships relatively difficult to implement. They require will and mutual respect on all sides and a long-term commitment.

\section{Supporting Families with Young Children through Community-Based Preschool Services}

In Azerbaijan the practice of PPP is rather new. The major initiative in this field was the 2012 Order of the Cabinet of Ministers on "Approving the rules on state order to individuals, legal entities, including NGOs in the field of social services." The Order is directed to implementing duties in social services, including social programs, projects and separate activities in this field. Based on competition among qualified contractors, this is an official step towards involving a wide range of stakeholders in delivery of social services. The funding for these public services is provided by state budget upon the agreement with the Ministry of Finance. The contractor submits monthly or quarterly reports to the state authority in accordance with the length/duration of the social services. Whereas the responsibility of 
designing and preparing the work plan of service delivery is not specified, it is subject to approval by the state authority and can be changed only upon written agreement between parties.

The partnership framework invites a wide range of partners, including municipalities, to deliver social services. Whereas this directly speaks to delegating state responsibilities onto different factors, financing is fully provided by state authorities. This partnership happens within a framework of a contract where state authority has a complete oversight. The service projects are delegated to private actors that meet qualification criteria set by the contractor (state). As the legal framework specifies the results, reports and related documents of the services are considered as property of the state. Thus the ownership is ultimately of the government. Ministry of Labor and Social Protection of Population has been making an extensive use of this partnership, particularly with NGOs to deliver social services by private providers under the Presidential Decree. According to the Ministry official, this initiative is innovative in itself, because in the Azerbaijani context it is not a common practice to delegate state duties to private sector representatives.

Because local communities do not have the funds to support quality preschools, traditional privatization is not an option if early childhood education is to target Azerbaijan's communities where 0-5 aged children are out of preschool and become part of the human capital development. However, different forms of public-private partnerships have the potential to both increase the quality of preschool provision and make the expansion of services across Azerbaijan financially viable. Unlike the 2006-privatization attempt, in a PPP the government would keep the ultimate responsibility for delivery of preschool services, but work in partnership with other organizations throughout the delivery process. This entails cooperation on project planning and design as well as clear separation of responsibilities for implementation and evaluation.

The importance of extending PPPs from social services to preschool education in particular is important from the following aspects. Discussing various financing mechanisms of ECD programs, Naudeau et al. (2010) suggest PPPs are usually established to raise "matching" funds, especially for large-scale capital improvement initiatives. The low level of access to preschool services necessitates making quality preschool available across the country into large-scale capital initiative. In addition, expansion of state-only sponsored ECD programs such as 
current preschools would mean a large financial burden on state budget. On the other hand, PPPs offer different streams of funding sources such as government, private enterprises, municipalities, foundations and community groups (p.174). PPP-based ECE programs can also offer programming flexibility that cannot be offered by centralized state-sponsored kindergartens. The partially decentralized structure of this model would allow for different community needs to be met.

In 2011 the Center for Innovations in Education piloted a community-based preschool project funded by the British Petroleum and the Ministry of Education in one of the rural areas of western Azerbaijan (Shamkir rayon). The project was implemented in partnership with the local municipality of the Shamkir region and was initiated as a result of the high demand for preschool services in the village. The "Community-based Preschool Services" is developing alternative school readiness programs for 5-6 year old children in the Shamkir region as a viable and sustainable community-based alternative to public preschool institutions fully funded by the state.

The first step of the project was a needs assessment for preschool services in the community. Findings from the project's needs assessment study show that even when state preschool institutions are present in a rural community, they typically do not cover the needs of all families. For example, the study shows priority at state preschools is given for admission of children with working mothers, and others are put on the waiting list because an unemployed mother is assumed to be able to provide home-based care. Whereas the overwhelming majority of the parents expressed their will to send their children to kindergarten, other obstacles included either lack of a preschool institution nearby or lack of transportation to the existing kindergartens.

Naudeau et al. (2010) suggests the following principles that need to be considered while deciding on funding source and allocation mechanisms:

1. Simplicity in terms of administration and access.

2. Reliability and sustainability of funding streams.

3. Likely burden of specific types of taxes on different population segments

4. Enforceability of regulations and standards to ensure a program's quality

5. Availability of parental choice and opportunities for direct financing across 
ECD providers, including home provision (particularly important in rural, isolated communities). (p.175)

Whereas not all of these principles may be content-relevant, the current structure of the center offers a simple structure under direct management of a director of the center. Two teachers of the center and the head of municipality established the Child Development Center offering preschool services as a Limited Liability Company. As a legal entity it is a new stage of its operations and the size of the target group it serves is small averaging 30 children. Launched first through funding support of BP, the Center developed its self-sustainable model with service user fees. The fees are agreed with community members thus allowing for affordability and accessibility of the preschool services for the families. The Center still needs to develop clear regulations and quality assurance mechanism. Parents' involvement and support is welcomed in the work of the Center. Quality of service is monitored by the implementing NGO, who in turn is checked by the donor agency (BP). However, in order to expand this model nationwide, the state, both local government and the Ministry of Education should take a larger partnership role in regulating and monitoring services, providing a simple path toward registration, and facilitating the step-by-step implementation across Azerbaijan. A phased implementation plan could provide the perfect opportunity to conduct a randomized study on the impact of preschool opportunities on rural children.

The project aimed to increase access to quality preschool education in the selected communities of Shamkir. According to the conducted single subject evaluation results, project reporting, and anecdotal evidences from parents and first-grade teachers of the village, the short-term effects of this ongoing project show that children who attended the Center show better social and educational results in primary grades compared to those who attended the public kindergarten in the village and those who did not attend any preschool education. These are promising indicators; however, more comprehensive research is needed to identify the span and long-term effects of this community-based preschool on children's development.

The ownership of the Center is given to community educators and the local municipality as a legal entity. The current Director of the Center was unanimously selected for her leadership that is informally recognized in the community. Overall the governance model of the Center is based on democratic principles. It is governed by the board comprised of local authorities, community leaders and 
parents. Community-based preschool solutions provide a possible cost-effective and quality way to bridge the demonstrated gap in preschool access in Azerbaijan's rural areas. The model involves opening a new, low-cost preschool in rural villages by selecting, hiring and training local unemployed former pedagogues (done by the implementer-CIE), in-kind contribution from the local municipality such as granting workspace, creating a learning environment, providing accounting services, and financing the refurbishment of the space (the whole project is financed by BP). Trained in child-centered education methods, the pedagogues work part-time; they run 2-hour education sessions, five days per week. They gradually assume ownership of their preschool, turning it into a small private business. Pricing decisions are made by parents and staff together and were 8 AZN per month ${ }^{10}$ in the first preschool located in DellerJeyir. Thus, the preschool becomes self-sustainable in the long run. The model only requires a one-time capital investment as a grant for instance, and then becomes fully financially viable (with continued municipal support for equipment maintenance).

From the perspective of the different stakeholders involved, this model suggests multi-layered desired outcomes. For private sector and corporate stakeholders, the PPP model for preschool services may present a model to achieve more sustainable social benefit in realization of their corporate social responsibility. In addition, the small scale of this model better enables educational services to meet the diverse needs of communities and beneficiaries. In the example of the CIE project, the community-based PPP model suggests several components that may help to increase the return on national education investment. Firstly, the hiring and training of qualified but unemployed professionals develops both the unemployed former educators and children in the community. Considering the insufficient number of preschool and overall ECE services, which are highly centralized in urban areas of Azerbaijan, an approach that utilizes untapped local resources facilitates the expansion of preschool services to rural areas and to areas outside the capital in general.

Mutual dependency seems to be at the core of a successful partnership. This speaks to the shared allocation of resources and interdependency among partners. By aligning goals and resources of the involved partners - NGO expertise in ECD, municipality support in reaching out to communities and financing by private actor, this model contributes to the overall national objectives of increased quality

\footnotetext{
${ }^{10}$ Average monthly per capita wages and salaries is 109.5 AZN http://www.maliyye.gov.az/en/node/941
} 
preschool access. The community-driven nature of such a partnership allows deploying different resources from different stakeholders, including nonprofits, private businesses, and local municipalities to sustain it, and in the long run this translates to complementary provision of services to the state budget.

In addition to state social safeguards, the Law on the Status of Municipalities specifies an additional social allowance for particular categories of citizens, which may be paid on permanent or single basis. The aim of these local social protection and social development programs are to address the issues in addition to or those issues that are not considered in the social development programs that the state is implementing. As noted in the Law these programs also include preschool education and development. Thus the legislative framework provides an opportunity to expand the municipality's role through PPP.

\section{Conclusion}

As discussed in the beginning of this paper the importance of ECED for the economic and social development of Azerbaijan requires immediate investment. Lack of timely investment would mean in aggregate higher costs for the public budget and society. Policymakers need to consider alternatives that would complement overall preschool provision in the country. This paper provided an overview of the role of PPP in delivering public services. Largely used in infrastructure projects, PPP has also been expanding to public services such as health and education services. This paper applied the same framework on a pilot project about community-based preschool services.

Despite its small scale the Child Development Center project has a potential to grow and inform policymakers and policymaking process about expansion of preschool services in Azerbaijan. First of all, desired targeting of universal coverage should be recognized by the government to make financing alternatives valid. State leadership involving inter-sectoral partners to design and implement ECD programs needs to be established. Up to date, alternative PPP models for preschool programs have been pilot initiatives by NGOs on a smaller scale. If increased access to preschool services compared to European standards is to be achieved, government (such as the Ministry of Education) should take the leadership to invite qualified actors for service delivery. At the preliminary stage, the model used by the MSLPP to delegate social services can be applied with certain modifications that respond to the needs of specific target groups and ECD 
programming. This can be done in the form of a Request for Proposal or an open competition. Whereas the importance of this policy is in involving different actors in delivery of public services, in the current practice of PPP in social services the funding is still entirely the burden of the state party and public budgets. Source of funding and duration of surfaces raises concern about the sustainability of this type of partnership between government and inter-sectoral actors.

\section{REFERENCES AND NOTES:}

Brinkerhoff, J. M. (2002). Government-nonprofitpartnership: a definingframework. PublicAdministrationandDevelopment, 22(1), 19-30.

Calman, L., \& Tarr-Whelan, L. (2005). Early Childhood Education for All: A Wise Investment . Recommendations arising from "The Economic Impacts of Child Care and Early Education: Financing Solutions for the Future" (pp. 1-69). New York: Legal Momentum .

Forrer, J., Kee, J. E., Newcomer, K. E., \& Boyer, E. (2010). Public-Private Partnerships and the Public Accountability Question . Public Administration Review , 475-484.

Hanushek, E. A., \& Wößmann , L. (2007). The Role of Education Quality in Economic Growth. World Bank Policy Research Working Paper 4122 .

Heckman, J. J. (2006). Skill Formation and the Economics of Investing in Disadvantaged Children. Science, 1900-1902.

International Association for the Evaluation of Educational Achievement (IEA) . (2012). PIRLS 2013 International Results in Reading. Ina V.S. Mullis, Michael O. Martin, Pierre Froy, and Kathleen T. Drucker. TIMSS \& PIRLS International Study Center, Lynch School of Education, Boston College and IEA.

Jütting, J. (1999, December). Public-private-partnership and social protection in developing countries: the case of the health sector. In Paper presented at the ILO workshop on "The extension of social protection (Vol. 13, pp. 14-12).

Klaus Schwab, World Economic Forum. (2012). The Global Competitiveness Report 20122013. Geneva: The World Economic Forum.

National Scientific Council on the Developing Child. (2007). The Timing and Quality of Early Experiences Combine to Shape Brain Architecture: Working Paper \#5.

Naudeau, S. K. (2010). Investing in Young Children. Washington, DC: World Bank.

OECD. (2011). Competitiveness and Private Sector Development: Eastern Europe and South Caucasus 2011: Competitiveness Outlook. OECD Publishing .

OECD (2012), Starting Strong III: A Quality Toolbox for Early Childhood Education and Care, OECD Publishing.

Vegas, E., \& Santibanez, L. (2010). The Promise of Early Childhood Development in Latin America and the Caribbean. Washington: World Bank.

Schwab, K. (2012). The Global Competitiveness Report 2012-2013. World Economic Forum.

Yescombe, E. R. (2011). Public-Private Partnerships: Principles of Policy and Finance. Butterworth-Heinemann. 


\title{
SUMMARY
}

\section{Exploring Public-Private Partnership in Preschool Education Provision:}

\section{Potential for Socio-Economic Development}

\author{
Vitaly Radsky \\ Center for Innovations in Education, Baku, Azerbaijan \\ Aynur Nabiyeva \\ Center for Innovations in Education, Baku, Azerbaijan \\ Ulviyya Mikayilova \\ Center for Innovations in Education, Baku, Azerbaijan
}

\begin{abstract}
This paper explores the role of public-private partnerships in expanding access to preschool education. The first part of the paper summarizes global findings on the importance of quality early childhood education (ECE) for child development, participation of parents in the labor market and overall human capital development of a society. The second section provides a brief overview of the current ECE situation in Azerbaijan. The final section presents a community-based preschool model that was piloted in the Shamkir region by the Center for Innovations in Education (CIE), a Baku-based nonprofit organization as a model for expansion of ECE education in Azerbaijan. Developed as a partnership between a nonprofit, local municipality and a private business, the model offers an opportunity to increase access to ECE nationwide, particularly in rural areas where availability of ECE services is a major issue. Given the multi-faceted benefits of early childhood education (ECE) and quality childcare, this paper suggests that introducing alternative models of preschool education on national level can contribute to socio-economic development in Azerbaijan.
\end{abstract}

Keywords: early childhood education, public-private partnership, socio-economic development 